interference. Mr. Wright of Nottingham, cut down and relieved a very tight stricture. To the inside, and close to the knuckle of gut, lay an enlarged gland, which helped to complicate the diagnosis in the first instance. The parts never recovered themselves, and the patient succumbed eight hours after the operation.

\section{THE EFFECT OF TIGHT LACING UPON THE SECRETION OF BILE.}

BY W. J. Colring, M.D., M.S., B. Sc. Lond.,

GOID MEDALLIST IN PUBLIC HEALTh, FELLOW OF THE ROYAL COLLIEGE OF SURGEONS OF RNGLAND.

THE evil effects and visceral deformities apt to supervene upon habitual restriction of the lower ribs have been the theme of innumerable lecturers and scribes. If warning and denunciation were operative, waists like that of the Venus of Milo would be neither few nor far between; but fashion cares little for the preaching of pathology, and, still regardless of the facts of anatomy, looks to the wasp for the ideal of what the nexus between thorax and abdomen ought to be. The effects of cramping the chest movements upon lungs and heart, liver and stomach, and the rest, have been for the most part described in vague and indefinite generalisations. Some recent observations I have made appealed so emphatically to my mind that I venture to think their publication advisable.

In the course of a series of observations upon the secretion of bile, which I have undertaken at the instigation of Dr. Lauder Brunton, I had occasion to make biliary fistulæ upon several anæsthetised guinea-pigs. I was very soon struck by the considerable effect which respiratory movements had upon the passage of bile along the cannulæ. With each descent of the diaphragm there was advance of the column of bile, and with each expiration a slight retrogression or arrest of advance. Moreover, powerful respiratory exertion considerably augmented the outflow, and even the slightly accelerated respiration which accompanied the administration of ether was not without its distinct effect. It occurred to me to see what would be the result of placing a constricting band around the lower part of the thorax. I accordingly selected a guinea-pig in which the biliary discharge from the cannula was free and in full quantity, and I collected the amount of bile secreted at regular intervals until a fair average could be obtained. $I$ then tied a tape band about on $\theta$ inch wide round the guinea-pig's waist (if such, by courtesy, can be allowed to exist), reducing the circumference thereof from five inches and a quarter to four inches, but not so as to cause any formidable risk of dyspnoea. After collecting the bile secreted at stated intervals, I removed the "stays" and again collected as before. I found that before the tight lacing began bile was being secreted at the rate of 8.4 cub. cents. per hour; during the tight lacing this fell to the rate of 45 cub. cent. per hour, and after the removal of the constriction ayain rose to $78 \mathrm{cub}$. cent. per huur. I repeated the experiment in other animals with the same result; so that it would appear that by reducing the circumference of the lower part of the thorax by about one-fourth, the bile secretion is reduced about one-half. It is useless to assert that it is bile expulsion, not bile secretion, that we are dealing with here, for the bile being secreted at a pressure very slightly above that of blood pressure, the mere presence of bile in the canaliculi is to some extent detrimental to secretion behind it; whereas the rapid evacuation of the bile channels, which free diaphragmatic movement ensures, is salutary to increased elimination of bile.

The free and unfettered action of the diaphragm, then, is essential to normal biliary secretion, and effects evacuation of the bile ducts much in the same way as succussion of the liver which saddle exercise affords, and which led Sydenham to opine that "the outside of a horse is the best thing for the inside of a man." This being so, what must be the effect of chronic restraint in those whose waists are for ever "cabined, cribbed, confined" by corsets with clasped steels and constricting laces? It is such as we might anticipate and have often seen, and the above merely points our knowledge and makes it more precise. Deficient bile, dyspepsia, sickness, constipation, clayey stools, headaches, chlorosis, debility, form a natural sequence, and one far from unfamiliar. Alas, the remedy is too simple to be thought worthy of consideration, too much within the patient's own control to run a chance of being carried out. For of course no woman ever yet tight laced herself; habit has become so much a second nature, the ideal wasp waist so ingrained in the sex. so intensified by inheritance, that there is much of bona fides in the invariable disclaimer. Be it so. If no woman "pinches" she will not object to employ elastic laces, which at best in her case will be a superfluity, and may not improbably permit a reversion to the waists of the Capua and Canova along with a measure of relief to the liver and its secretion.

\section{SPONTANEOUS EVACUATION OF A LARGE GALL-} STONE.

BY W. H. Johnson, M.R.C.S.

ON Feb. 2nd of this year I was called in to see Mrs. Gaged fifty-nine, an old patient of mine, whom I had frequently attended for attacks of syncope and other symptoms dependent on fatty heart. The messenger described her as having been seized with most intense pain and vomiting, the attack coming on suddenly after dinner, which tho patient had enjoyed as usual; in fact, she was stated to have been quite well up to the moment of attack. Having ascertained there was no hernia, I gave a hypodermic injection of ether, ordered a hot poultice to be applied to the abdomen and a clyster of warm soap-and-water to be administered. I abstained from giving opium for the time being. In two hours I saw her again, and found her still in constant pain, with exacerbations, but no marked tenderness; bilious vomiting; the collapse not so extreme; no sign of jaundice on the skin or conjunctiva; and, as I had previously ascertained, constipation since the preceding evening. I injected one-third of a grain of morphia subcutaneously, which dulled the pain somewhat.

I need not go through the progress of the case. For the next two or three days it presented all the phenomena of acute intestinal obstruction; the symptoms were treated on general principles, and the strength maintained, as well as could be, by nutritive enemata and small quantities of iced champagne. On the evening of the third day I could feel distinctly, and called the attention of the attendant to, a rounded mass at the left and slightly below the level of the umbilicus; the pain continued very intense and the romit suspicious. On the morning of the fourth day the substance was not perceptible, the obstruction was as complete as ever, the pain as acute, especially in the right iliac region, and the vomit unmistakably fæcal. The temperature which had hitherto been rather below the normal, rose to close on $99^{\circ}$. At 8 A.Mr. on the fifth day the patient expressed herself as feeling much easier, and the vomiting was less frequent; she looked altogether brighter, and had slept a little: About 3 P.M. a semi-liquid motion was passed, and the bowels acted again twice between that, time and $8 P_{M} M_{1}$ when with the last stool, after some straining, a large stone was expelled with considerable force into the bedpan. I had asked them to keep all that passed for inspection. At the next visit the patient was much better, although the stomach remained very irritable. A rather severe attack of enteritis, which kept the patient in bed a month, delayed the convalescence, but she is now quite well. The stone is round, tuberculated on the surtace, non-facetted, and measures $3 \frac{3}{8}$ in. in circumference.

The noticeable points in this case are as follows:-1. The size of the stone. 2. Its passage, as proved by the symptoms, by ulceration direct from the gall-bladder to the duodenum being unmarked by any previous pain or inconvenience. This is, I imagine, uncommon, although Mr. Treves, in the Jacksonian prize essay of 1883, says: "In several cases the establishment of a fistulous communication between the gall-bladder and the duodenum appears to have been effected without producing any noticeable symptom." 3 . The probability, as I take it, of having felt the stone in the small intestine through the abdominal wall, and being able, by the symptoms caused, to trace it to its temporary stoppage at the ileo-cæcal valve. I certainly felt much more satisfied after the disappearance of the tumour, and am pretty well assured that it was the stone on its travels. 